\title{
Quantitative dynamics of triacylglycerol accumulation in microalgae populations at single-cell resolution revealed by Raman microspectroscopy
}

Tingting Wang ${ }^{1+}$, Yuetong $\mathrm{Ji}^{1+}$, Yun Wang ${ }^{1}$, Jing Jia ${ }^{1}$, Jing $\mathrm{Li}^{1}$, Shi Huang ${ }^{1}$, Danxiang $\mathrm{Han}^{3}$, Qiang Hu${ }^{3}$, Wei E Huang ${ }^{2^{*}}$ and Jian $\mathrm{Xu}^{1^{*}}$

\begin{abstract}
Background: Rapid, real-time and label-free measurement of the cellular contents of biofuel molecules such as triacylglycerol (TAG) in populations at single-cell resolution are important for bioprocess control and understanding of the population heterogeneity. Raman microspectroscopy can directly detect the changes of metabolite profile in a cell and thus can potentially serve these purposes.

Results: Single-cell Raman spectra (SCRS) of the unicellular oleaginous microalgae Nannochloropsis oceanica from the cultures under nitrogen depletion (TAG-producing condition) and nitrogen repletion (non-TAG-producing condition) were sampled at eight time points during the first 96 hours upon the onset of nitrogen depletion. Single $N$. oceanica cells were captured by a 532-nm laser and the SCRS were acquired by the same laser within one second per cell. Using chemometric methods, the SCRS were able to discriminate cells between nitrogen-replete and nitrogen-depleted conditions at as early as 6 hours with $>93.3 \%$ accuracy, and among the eight time points under nitrogen depletion with $>90.4 \%$ accuracy. Quantitative prediction of TAG content in single cells was achieved and validated via SCRS and liquid chromatography-mass spectrometry (LC-MS) analysis at population level. SCRS revealed the dynamics of heterogeneity in TAG production among cells in each isogenic population. A significant negative correlation between TAG content and lipid unsaturation degree in individual microalgae cells was observed.

Conclusions: Our results show that SCRS can serve as a label-free and non-invasive proxy for quantitatively tracking and screening cellular TAG content in real-time at single-cell level. Phenotypic comparison of single cells via SCRS should also help investigating the mechanisms of functional heterogeneity within a cellular population.
\end{abstract}

Keywords: Microalgae, Triacylglycerol, Single-cell Raman spectra, Bioprocess dynamics, Population heterogeneity

\section{Background}

Microalgae represent promising biomass feedstock for fuels because of their ability to grow rapidly and synthesize large amounts of storage chemical compounds from sunlight and carbon dioxide. They can be cultivated in

\footnotetext{
* Correspondence: xujian@qibebt.ac.cn; w.huang@sheffield.ac.uk ${ }^{\dagger}$ Equal contributors

'Single-Cell Center, CAS Key Laboratory of Biofuels and Shandong Key Laboratory of Energy Genetics, Qingdao Institute of BioEnergy and Bioprocess Technology, Chinese Academy of Sciences, 189 Songling Road, Qingdao, Shandong 266101, China

${ }^{2}$ Kroto Research Institute, University of Sheffield, Broad Lane, Sheffield, South Yorkshire S3 7HQ, United Kingdom

Full list of author information is available at the end of the article
}

non-arable land, non-potable water, and waste streams (such as flue gases and wastewaters), thus posing little competition to food crops while providing environmental benefits $[1,2]$.

In response to environmental changes, microalgae efficiently modify lipid metabolism and result in a variety of cellular lipid patterns, including neutral lipids, polar lipids, wax esters, sterols and hydrocarbons [3]. Significant accumulation of neutral lipids in microalgae cells (for example 20 to $50 \%$ dry cell weight), mainly in the form of triacylglycerol (TAG), was demonstrated under unfavorable environmental or stress conditions such as nutrition 
limitation. TAGs serve primarily as carbon and energy storage in the form of dense lipid bodies in the cell and are considered as one ideal source for biodiesel [4]. Therefore, quantitative evaluation of the cell growth status and the cellular TAG content is essential for bioprocess monitoring and engineering for efficient and scalable biofuel production.

Sophisticated methodologies presently used for quantitation of cellular metabolite changes during bioprocesses, such as chromatography, mass spectrometry and nuclear magnetic resonance (NMR), are not only time and labor consuming, but also have mostly measured the stochastic average of the population, leaving phenotypic variations among individual cells masked [5-7]. However, functional diversity and phenotypic heterogeneity of microbial cellular behaviour have long been recognized among an isogenic population, such as those in cell growth, stress resistance, metabolites accumulation and other bioprocesses [8]. Such cell-to-cell variations of phenotypes have been shown to be crucial for the cells to adapt to fluctuating environments [9]. The averaged phenotypes in different populations may be similar, but their phenotypic distribution patterns at single-cell level can be dramatically different, which have significant impact on the populations' functional stability and response to sudden changes such as stress or nutrient depletion $[10,11]$. Therefore, strategies for phenotypic measurement at single-cell resolution are of significant importance.

Raman microspectroscopy, which directly detects vibrations of biochemical bonds through the inelastic scattering by a laser light [12], provides a solution for rapid determination of metabolic fingerprint in real-time, as well as considerable improvements in speed [13]. Single-cell Raman microspectroscopy, combined with optical tweezers, enables the capture and subsequent acquisition of single-cell Raman spectra (SCRS) of individual live cells [14], thus serving as a biochemical fingerprint of a cell $[15,16]$. This label-free and in situ measurement property offers great advantages to the commonly used fluorescence based methods for the illustration of cellular lipid (such as Nile red) [17]. Related applications include confirmation of the existence of TAG in two algal species Chlorella sorokiniana and Neochloris oleoabundans [18], characterization of the structure and location of liquid hydrocarbons within Botryococcus braunii cells [19], calculation of total unsaturation and the number of double bonds in the hydrocarbon chains of microalgal lipids [20], as well as estimation of the total lipid abundance in Chlorella vulgaris pastes [21]. However, these previous studies have only focused on the general characteristics of cellular lipids and were not able to determine the cellular content of a particular lipid class of interest, either on single cells [18-20] or on pastes [21]. Moreover, these studies have required minutes for Raman signal acquisition in each SCRS measurement [18-20], which precluded many applications where throughput of measurement is important (such as temporal tracking of bioprocess). Quantitative assessment of specific lipid class (like TAG) at single-cell resolution with sufficient throughput is therefore yet to be achieved for the monitoring of bioprocess dynamics.

Nannochloropsis spp. are a group of unicellular oleaginous microalgae of particular industrial interests [22]. Here, using nitrogen-depletion triggered oil production of Nannochloropsis oceanica as a model, we sampled SCRS from nitrogen depletion (Group N-) and nitrogen repletion (Group $\mathrm{N}_{+}$) cultures at eight time points during the first 96 hours upon the onset of TAG accumulation. We show here that the SCRS, acquired within one second per cell, are able to discriminate cells between the two nutrition conditions at very early growth stage $(6 \mathrm{~h})$, and distinguish $\mathrm{N}$-depleted cells among different time points with high accuracy. We further demonstrate quantitative prediction of TAG content in single cells via the SCRS, as well as reveal the dynamics of phenotypic heterogeneity, and the significant negative correlation between TAG content and lipid unsaturation degree among individual cells.

\section{Results and discussion}

Temporal tracking of triacylglycerol production in an isogenic population of microalgal cells

Group N- cells showed a slower growth than Group N + cells. The optical density at $750 \mathrm{~nm}\left(\mathrm{OD}_{750}\right)$ of N- Group cultures at 96 hours (the early stationary phase) reached $7.66 \pm 0.05$, which were approximately two-thirds of that of the Group N + cultures $\left(\mathrm{OD}_{750}=12.09 \pm 0.06\right)$. However, liquid chromatography-mass spectrometry (LC-MS) measurement showed that Group N-cells accumulated a significant amount of TAG, whereas little was observed in the Group N + cells. At 96 hours, the TAG content of Group N- cells reached $412.32 \pm 13.13 \mathrm{mg} \mathrm{g}^{-1}$ dry weight while that of the Group $\mathrm{N}+$ cells remained low $\left(1.73 \pm 0.20 \mathrm{mg} \mathrm{g}^{-1}\right.$ dry weight).

For SCRS acquisition, a single $N$. oceanica IMET1 cell was optically trapped by a $532 \mathrm{~nm}$ laser and its Raman spectrum was recorded by the same laser. The typical acquisition time for a well-resolved spectrum of a microalgae cell was within one second. During the whole process, no loss of cell activity was observed, thus our measurement does not seem to have a significant negative impact on the health state of the cell (Additional file 1). This is also supported by our previous study which demonstrated that single bacterial cells were able to grow after trapping and SCRS measurement by a $532 \mathrm{~nm}$ laser [23]. In accordance with the difference in TAG production, both fingerprint region (800 to $1800 \mathrm{~cm}^{-1}$ ) and hydrocarbon region (2600 to $3100 \mathrm{~cm}^{-1}$ ) of SCRS exhibited very distinct patterns between Group $\mathrm{N}+$ and $\mathrm{N}-$ (Figure $1 \mathrm{~A}$ and $\mathrm{B}$ ). In the Group N- cells, intensities of all major lipid bands showed 


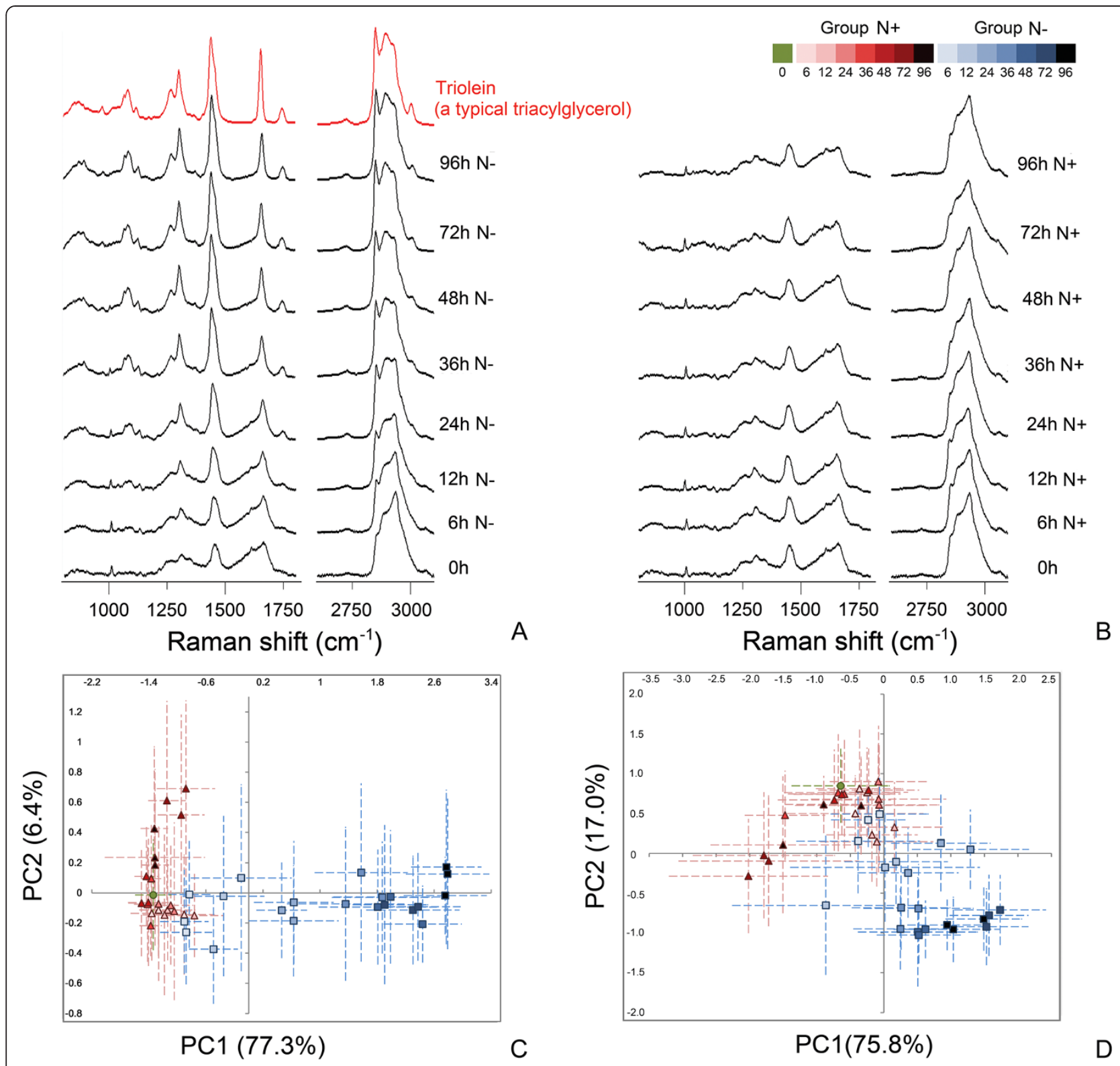

Figure 1 Tracking the microalgal oil production via SCRS. (A) Averaged SCRS of the 60 cells of Group N-at each time point as well as the Raman spectrum of triolein, a typical TAG species. (B) Averaged SCRS of the 60 cells of Group N + at each time point. (C) PCA scores plot derived from the fingerprint region. (D) PCA scores plot derived from the hydrocarbon region. Each symbol represents the average of twenty cells of a triplicate; the error bars represents SD of the twenty cells. Green diamond: cells at 0 h. Red triangle: cells of Group N+. Blue square: cells of Group N-. h: hours; PCA: principal component analysis; PC: principal component; SCRS: single-cell Raman spectra; SD: standard derivation;

TAG, triacylglycerol.

apparent increase along the cultivation time, including the bands representing chemical bonds attributed to chain unsaturation (1264 and $1656 \mathrm{~cm}^{-1}$ ) and saturation (1302, 1441, 2851 and $2889 \mathrm{~cm}^{-1}$ ) [20], and the $1746 \mathrm{~cm}^{-1}$ Raman band which indicates the ester specific chemical bond $\mathrm{C}=\mathrm{O}$ stretching vibration specifically derived from TAG [24]. Meanwhile, intensities of protein-relative bands (for example 1005, 1200-1350, and 1600-1700 $\mathrm{cm}^{-1}$ ) [25] decreased in the $\mathrm{N}$-group cells (Table 1). Note that all main peaks in the SCRS profiles of Group N- cells at the later time points starting from 36 hours were consistent with the profiles of triolein, a typical TAG species (Figure 1A). In contrast, the Group $\mathrm{N}+$ cells showed no change with these bands during the whole bioprocess (Figure 1B). These findings suggested a continuous TAG production by the cells, accompanied with a deficiency of protein biosynthesis under a nitrogen-deficiency condition, which was consistent with previous studies $[26,27]$. 
Table 1 List of major Raman bands discriminating between different states of the cells

\begin{tabular}{|c|c|c|}
\hline $\begin{array}{l}\text { Raman } \\
\text { bands }\left(\mathrm{cm}^{-1}\right)\end{array}$ & $\begin{array}{l}\text { Trend with time } \\
\text { in Group N- cells }\end{array}$ & Biological assignment/interpretation \\
\hline 1066 & $\uparrow$ & Lipid, Alkyl C-C gauche stretches \\
\hline 1080 & $\uparrow$ & $\begin{array}{l}\text { Carbohydrate, Carbohydrate } \\
\mathrm{C}-\mathrm{O}-\mathrm{H} \text { bending }\end{array}$ \\
\hline 1125 & $\uparrow$ & $\begin{array}{l}\text { Carbohydrate, } \mathrm{C}-\mathrm{O}-\mathrm{H} \text { deformation, } \\
\mathrm{C}-\mathrm{O} \text { and } \mathrm{C}-\mathrm{C} \text { stretches }\end{array}$ \\
\hline 1264 & $\uparrow$ & Lipid, Alkyl =C-H cis stretches \\
\hline 1302 & $\uparrow$ & Lipid, Alkyl $\mathrm{C}-\mathrm{H}_{2}$ twist \\
\hline 1441 & $\uparrow$ & Lipid, Alkyl $\mathrm{C}-\mathrm{H}_{2}$ bend \\
\hline 1656 & $\uparrow$ & Lipid, Alkyl C=C stretches \\
\hline 1746 & $\uparrow$ & Lipid, Ester $\mathrm{C}=\mathrm{O}$ stretches \\
\hline 2851 & $\uparrow$ & \multirow{2}{*}{$\begin{array}{l}\text { Lipid, carbohydrate, } \mathrm{C}-\mathrm{H}_{2}, \mathrm{C}-\mathrm{H}_{3} \\
\text { asymmetric and symmetric stretches }\end{array}$} \\
\hline 2889 & $\uparrow$ & \\
\hline 1003 & $\downarrow$ & Protein, Phenylalanine ring breath \\
\hline 1610 & $\downarrow$ & Protein Amide I \\
\hline
\end{tabular}

Up and down arrows indicate the Raman bands which increased or decreased in intensity during the growth of Group $\mathrm{N}$ - cells respectively.

The variation of Raman spectra between individual cells were observed within a population. To verify the reproducibility of the method, Raman profiles were generated by 20 continuous measurements on one cell of Group N- at 48 hours (Figure 2A), and compared to the Raman profiles of each of the 20 cells of all Group $\mathrm{N}$ - triplicates at the eight time points (Figure 2B). Variation was quantified using a standard deviation of the mean (SDM) as described previously [28]. The SDM values of the fingerprint region and hydrocarbon region for 20 measurements of one cell were 0.070 and 0.014 respectively, while those for 20 cells at eight time points were $0.254 \pm 0.070$ and $0.101 \pm 0.033$ respectively, showing that the variation of 20 measurements was much smaller than those of 20 cells. These results demonstrate the high reproducibility of SCRS measurement and reliable distinction of the biochemical property between the cells.

Principal component analysis (PCA) was a commonly used approach for the evaluation of the ordination of different observations. It is shown by PCA scores plots, based either on the fingerprint region or the hydrocarbon region, that while Group N + cells aggregated, Group $\mathrm{N}$ - cells showed a clear differentiation according to their growth time. The first principal component (PC1) explained $77.3 \%$ and $75.8 \%$ of the total variance respectively (Figure $1 \mathrm{C}$ and $\mathrm{D}$ ). The trend of differentiation was in accordance with the process of TAG accumulation, indicating that it may be responsible for the distinguishing of cells at different growth stages.

SCRS provides a sensitive biochemical 'fingerprint' to measure cell-to-cell variability. In this study, we have applied an optimized Raman microscope to obtain each

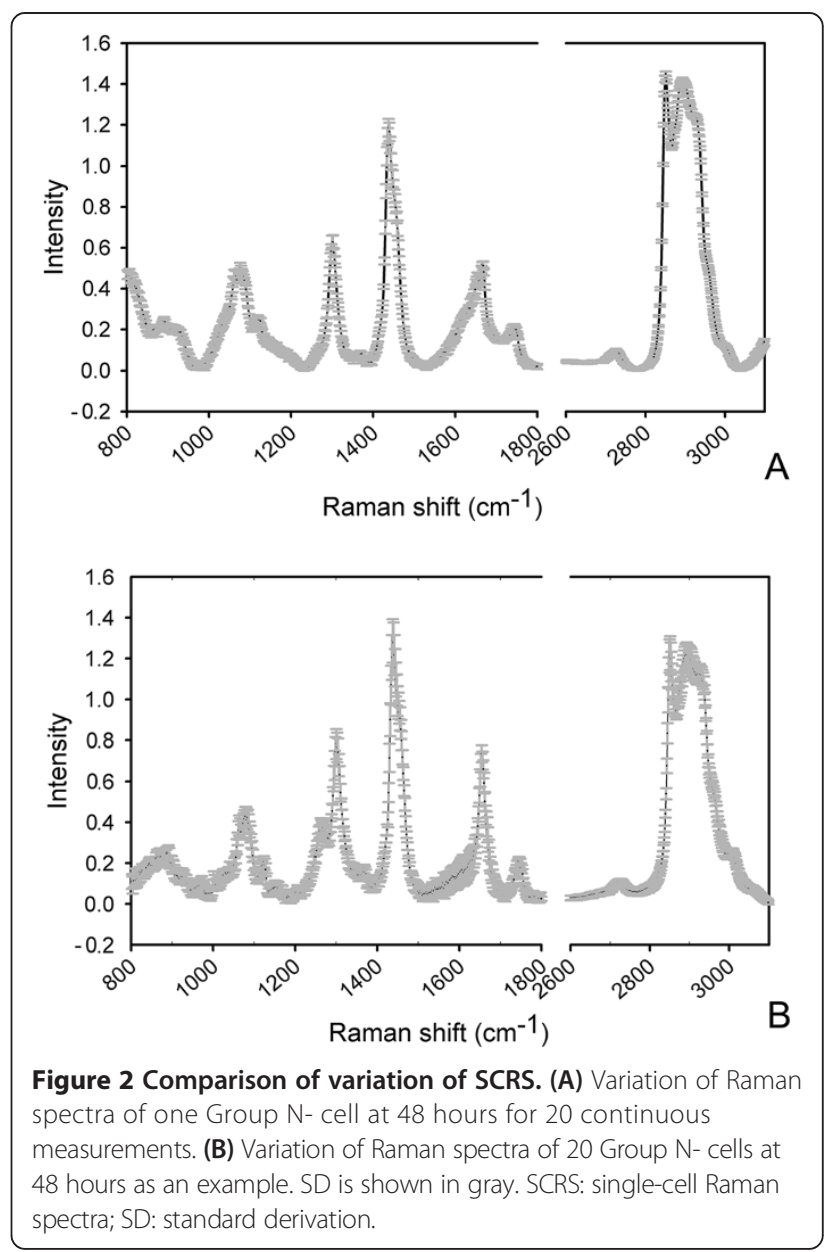

SCRS within one second. The improved Raman system was equipped with a short Raman light path, low noise and sensitive electron multiplying charge coupled device (EMCCD) for the Raman signal detection, and an appropriate incident laser of $532 \mathrm{~nm}$ [29]. Its sensitivity and throughput was over two orders of magnitude higher than a recent study whereby 120 seconds of prerequisite photobleaching and 10 seconds of the Raman signal acquisition were required for each SCRS measurement [20], and thus allows for screening of a large amount of cells in a short time, which is critical for the continuous monitoring of the entire bioprocess.

\section{Discrimination of cells from different temporal phases during the oleaginousness process}

The significant change of Raman spectra of individual cells enabled these cells to be further compared and discriminated. Linear discriminant analysis (LDA) in combination with PCA achieved highly accurate classification between cells under $\mathrm{N}$ - or $\mathrm{N}+$ condition at each time point. For the analysis using the fingerprint region of the Raman spectra, the misclassification rate was $6.7 \%$ at $6 \mathrm{~h}$ and decreased to $3.3 \%$ at $12 \mathrm{~h}$ and $24 \mathrm{~h}$ (validation data). For 
cells at each time point since $36 \mathrm{~h}$, all cells were classified to $\mathrm{N}$ - or $\mathrm{N}+$ groups correctly. The spectra of the hydrocarbon region also generated $100 \%$ correct classification at each time point starting from $24 \mathrm{~h}$, although the misclassification rates at the earlier time points were relatively higher $(16.7 \%$ at $6 \mathrm{~h}$ and $6.7 \%$ at $12 \mathrm{~h}$, validation data) (Table 2).

Principal component-linear discrimination analysis (PC-LDA) was also performed to temporally discriminate all Group N- cells between the seven different culture stages $(6,12,24,36,48,72$ and 96 hours) under nitrogen depletion and the cells at starting time point (0 hours). The first 20 principal components (PCs), which accounted for more than $90 \%$ of the whole variance, were used in the analyses. Using the fingerprint region of the Raman spectra, low misclassification rates of $6.1 \%$ for calibration data and $7.5 \%$ for validation data were achieved. In total, 31 out of 480 cells were classified incorrectly (assigned to a different growth stage from the actual one). PC-LDA using the hydrocarbon region of the Raman spectra generated similar results, with a misclassification rate of $10.0 \%$ for calibration data and $7.5 \%$ for validation data (Table 3 ).

Dynamic monitoring of the nutrient status of microalgae cells is important for manipulation of nutrient availability in algal biofuel production in order to optimize yields [30]. Single-cell Raman microspectroscopy was previously employed to distinguish the eukaryotic chlorophyte alga Dunaliella tertiolecta cells from N-replete and N-starved conditions after four days adaptation based on chlorophyll a and beta-carotene bands [31]. Here, we showed that SCRS is able to distinguish between $\mathrm{N}$-depleted and $\mathrm{N}$-replete conditions in oleaginous microalgae cells from as early as six hours under nitrogen depletion, which showed a significant improvement in sensitivity. Furthermore, we demonstrated for the first time the ability of
SCRS to temporally discriminate among the N-depleted cells $(6,12,24,36,48,72$ and 96 hour cultivations), which is important for the continuous monitoring of the oleaginousness process.

\section{Quantitative dynamics of triacylglycerol content in single cells}

To further investigate the TAG accumulation in the cells, we have developed a partial least square regression (PLSR) model to quantify the TAG content in individual Group $\mathrm{N}$ - cells at different time points. PLSR is a powerful tool in the development of calibration models for determination of particular parameters, with the advantage of dealing with spectra-containing overlapping signals and noises [32]. It is also widely used in the quantification of specific components in complicated chemical products [33] or fermentation broth [34]. Spectra of the fingerprint region were selected for modeling due to their better performance in PCA and LDA as described above.

For the 0 hour and Group N-cultures, the total TAG content determined by LC-MS increased from $1.23 \pm$ $0.27 \mathrm{mg} \mathrm{g}^{-1}$ dry weight at 0 hours to $412.32 \pm 13.13 \mathrm{mg} \mathrm{g}^{-1}$ dry weight at 96 hours, a 335 -fold increase in TAG. The PLSR model was established and validated using the averaged SCRS of all cells at 0 hours, and averaged SCRS of each triplicate at 6, 12, 24, 48, 72 and 96 hours, as well as the TAG content of the corresponding cultures by LC-MS. The optimal number of partial least square (PLS) components was set as seven. A highly reliable regression model was generated, with a mean squared error of calibration (MSEC) of 0.0854, with the correlation coefficient value $\left(\mathrm{R}^{2}\right)$ of 0.9997 for calibration dataset and 0.9465 for validation dataset. The overall correlation coefficient value $\left(R^{2}\right)$ reached 0.9790 (Figure 3). The TAG content of each Group N-cell at 6, 12, 24, 36, 48, 72 and

Table 2 Predictive modeling of nutrition condition of single cells

\begin{tabular}{|c|c|c|c|c|c|c|c|}
\hline \multicolumn{8}{|c|}{ Fingerprint region } \\
\hline & $6 \mathrm{~h}$ & $12 \mathrm{~h}$ & $24 \mathrm{~h}$ & $36 \mathrm{~h}$ & $48 \mathrm{~h}$ & $72 \mathrm{~h}$ & $96 h^{*}$ \\
\hline Number of PCs used in LDA & 9 & 9 & 2 & 2 & 2 & 2 & 2 \\
\hline Variations explained by these PCs (\%) & 67.5 & 82.0 & 72.6 & 89.1 & 91.1 & 85.7 & 93.6 \\
\hline MCR of calibration data (\%) & 2.2 & 2.2 & 1.1 & 1.1 & 1.1 & 1.1 & 0 \\
\hline MCR of validation data (\%) & 6.7 & 3.3 & 3.3 & 0 & 0 & 0 & 0 \\
\hline \multicolumn{8}{|c|}{ Hydrocarbon region } \\
\hline & $6 \mathrm{~h}$ & $12 \mathrm{~h}$ & $24 \mathrm{~h}$ & $36 h$ & $48 \mathrm{~h}$ & $72 \mathrm{~h}$ & $96 h^{*}$ \\
\hline Number of PCs used in LDA & 10 & 12 & 5 & 2 & 2 & 2 & 2 \\
\hline Variations explained by these PCs (\%) & 89.1 & 95.8 & 94.9 & 96.3 & 94.7 & 97.9 & 97.2 \\
\hline MCR of calibration data (\%) & 2.2 & 0 & 0 & 0 & 0 & 0 & 0 \\
\hline MCR of validation data (\%) & 16.7 & 6.7 & 0 & 0 & 0 & 0 & 0 \\
\hline
\end{tabular}

*For both calculations, one outlier was excluded from the training set at $96 \mathrm{~h}$.

PC-LDA results were shown for discriminating cells between Groups N- and N + at each time point. h: hours; LDA: linear discriminant analysis; MCR: misclassification rate by leave-one-out cross validation (LOOCV); PC: principal component. 
Table 3 Predictive modeling of growth stage of single cells

\begin{tabular}{|c|c|c|c|c|}
\hline & & & & \\
\hline & Calibration data & Validation data & Calibration data & Validation data \\
\hline & Number of cells & & Number of cells $r$ & \\
\hline $\mathrm{Oh}$ & $0(0)$ & $0(0)$ & $0(0)$ & $1(6.7 \%)$ \\
\hline $6 \mathrm{~h}$ & $0(0)$ & $1(6.7 \%)$ & $4(8.9 \%)$ & $2(13.3 \%)$ \\
\hline $12 \mathrm{~h}$ & $3(6.7 \%)$ & $1(6.7 \%)$ & $5(11.1 \%)$ & $1(6.7 \%)$ \\
\hline $24 \mathrm{~h}$ & $4(8.9 \%)$ & $1(6.7 \%)$ & $6(13.3 \%)$ & $1(6.7 \%)$ \\
\hline $36 \mathrm{~h}$ & $3(6.7 \%)$ & $2(13.3 \%)$ & $6(13.3 \%)$ & $1(6.7 \%)$ \\
\hline $48 \mathrm{~h}$ & $6(13.3 \%)$ & $1(6.7 \%)$ & $5(11.1 \%)$ & $0(0)$ \\
\hline $72 \mathrm{~h}$ & $1(2.2 \%)$ & $2(13.3 \%)$ & $6(13.3 \%)$ & $2(13.3 \%)$ \\
\hline $96 \mathrm{~h}$ & $5(11.1 \%)$ & $1(6.7 \%)$ & $4(8.9 \%)$ & $1(6.7 \%)$ \\
\hline Total & 22 (6.1\%) & 9 (7.5\%) & $36(10.0 \%)$ & $9(7.5 \%)$ \\
\hline
\end{tabular}

PC-LDA results were shown for discriminating Group N- cells at different time points. h: hours; MCR: misclassification rate by leave-one-out cross validation (LOOCV).

96 hours was then estimated through their Raman spectra by the established model. Among all 420 cells at the seven time points, the predicted TAG content of 22 cells were lower than the measured TAG content value of the 0 hour culture (1.23 $\mathrm{mg} \mathrm{g}^{-1}$ dry weight), including nine cells at 6 hours, eight cells at 12 hours and five cells at 24 hours. These cells were thus regarded as lower than the detection threshold and were discarded in the following analysis. The TAG content of individual cells also showed a continuous increase during cell growth (Figure 4A). The mean value of predicted cellular TAG contents of each triplicate showed significant correlation with the TAG content of the corresponding cultures by LC-MS (Pearson correlation, $r=0.9864, P<0.01$ ), suggesting that while revealing varied TAG content of individual cells, SCRS could also be an ideal representative for the overall feature of the corresponding population.

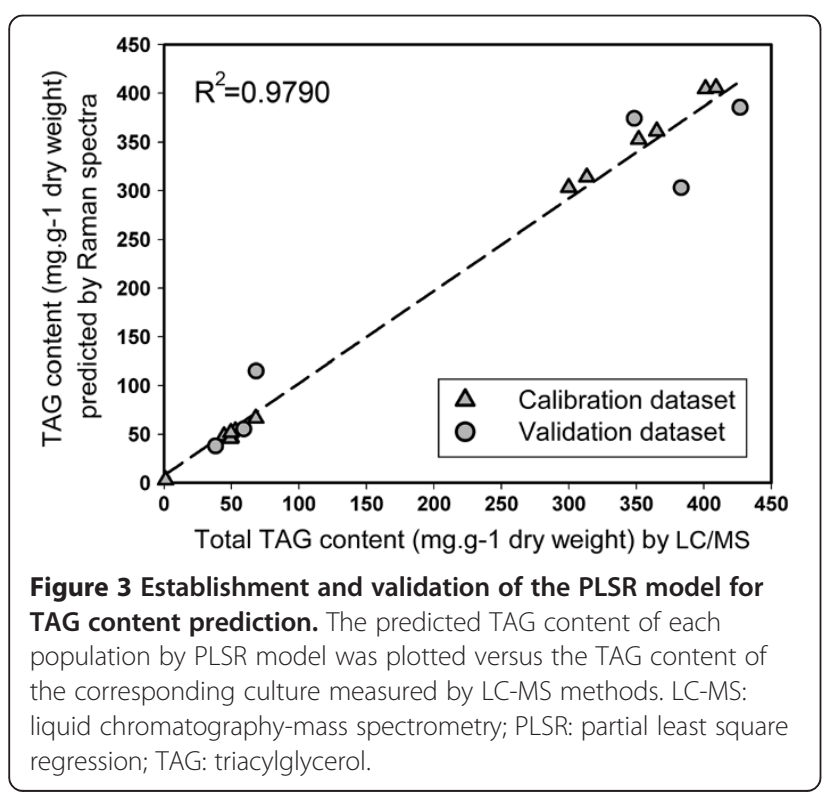

Lipid unsaturation degree is also a key parameter in the evaluation of biofuels. At the single-cell level, the changes of lipid unsaturation degree accompanying the TAG accumulation can be measured by $\mathrm{I}_{1656} / \mathrm{I}_{1441}$ of the Raman spectra, as reported previously [20]. To validate this method, the mean value of lipid unsaturation degree by SCRS of each of the 20 cells was calculated and compared with the population level lipid unsaturation degree calculated by LC-MS (Additional file 2). A significant positive correlation was revealed (Pearson correlation, $r=0.906, P<0.01$ ), supporting the ability of $\mathrm{I}_{1656} / \mathrm{I}_{1441}$ to estimate the unsaturation degree of total cellular lipid in the cell. Based on this method, we found that for individual Group N- cells, the degree of lipid unsaturation decreased sharply before 36 hours and stayed stable later on, showing a significant change during the growth (analysis of variance (ANOVA) test, $P<0.01$ ). However for individual Group $\mathrm{N}+$ cells, lipid unsaturation was relatively constant during 0 to 48 and 72 to 96 hours respectively, but showed an obvious decrease between 48 and 72 hours. The degree of lipid unsaturation of Group N- cells was significantly lower than Group $\mathrm{N}+$ cells at each time point after 6 hours (Student t test, $P<0.01$ ) (Figure 4B).

The estimated TAG content of each cell in Group $\mathrm{N}$ - showed a significant negative correlation with its lipid unsaturation degree (Spearman's rank correlation coefficient $p=-0.800, P<0.01$; Additional file 3: Figure S1A), which was consistent with the observation at the population level (TAG content of each Group N- culture versus its lipid unsaturation degree determined by LCMS, Spearman's rank correlation coefficient $p=-0.977$, $P<0.01$, Additional file 3: Figure S1B). Thus individual cells with a higher TAG content tend to possess more saturated lipids. Since both TAG contents and lipid unsaturation degree are key parameters in the evaluation of biofuels, the SCRS measurements can be used to screen for biofuel-producing feedstock or processes. 

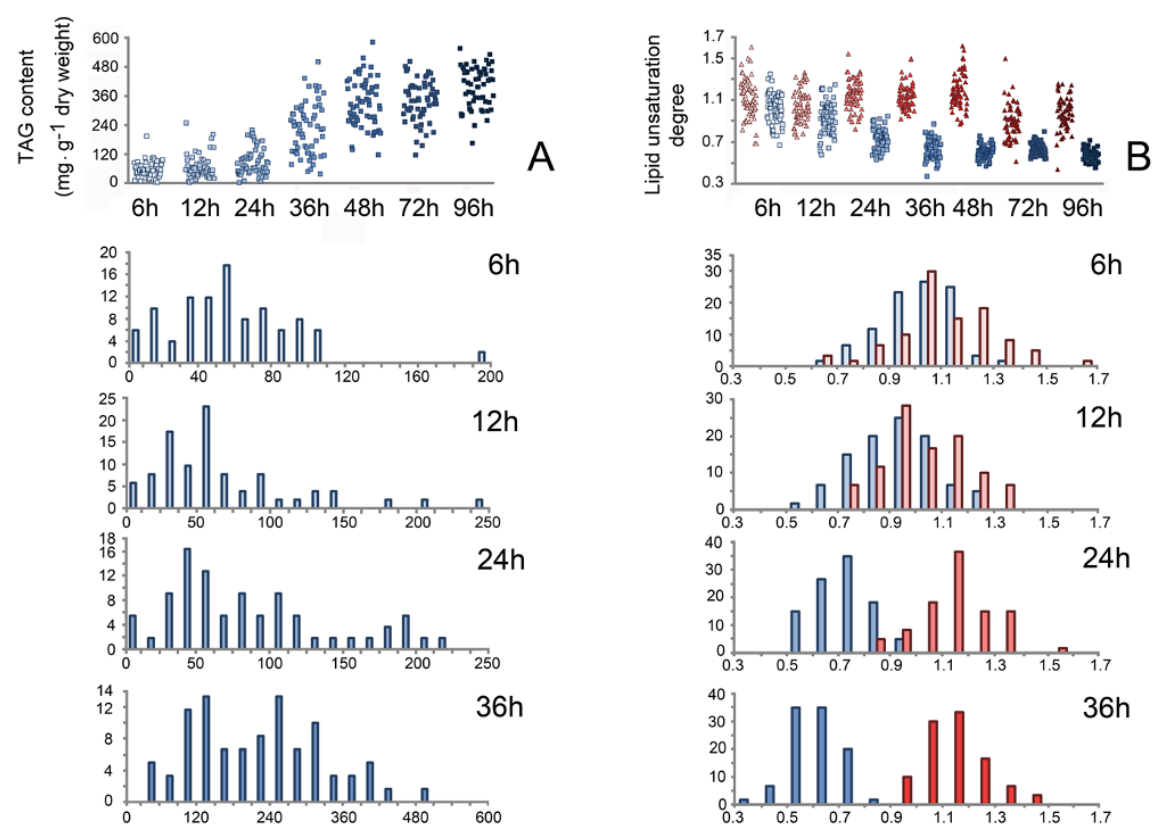

$12 \mathrm{~h}$

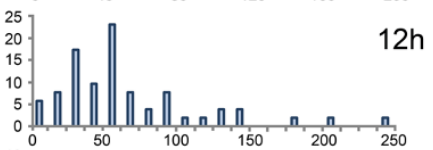

$24 \mathrm{~h}$
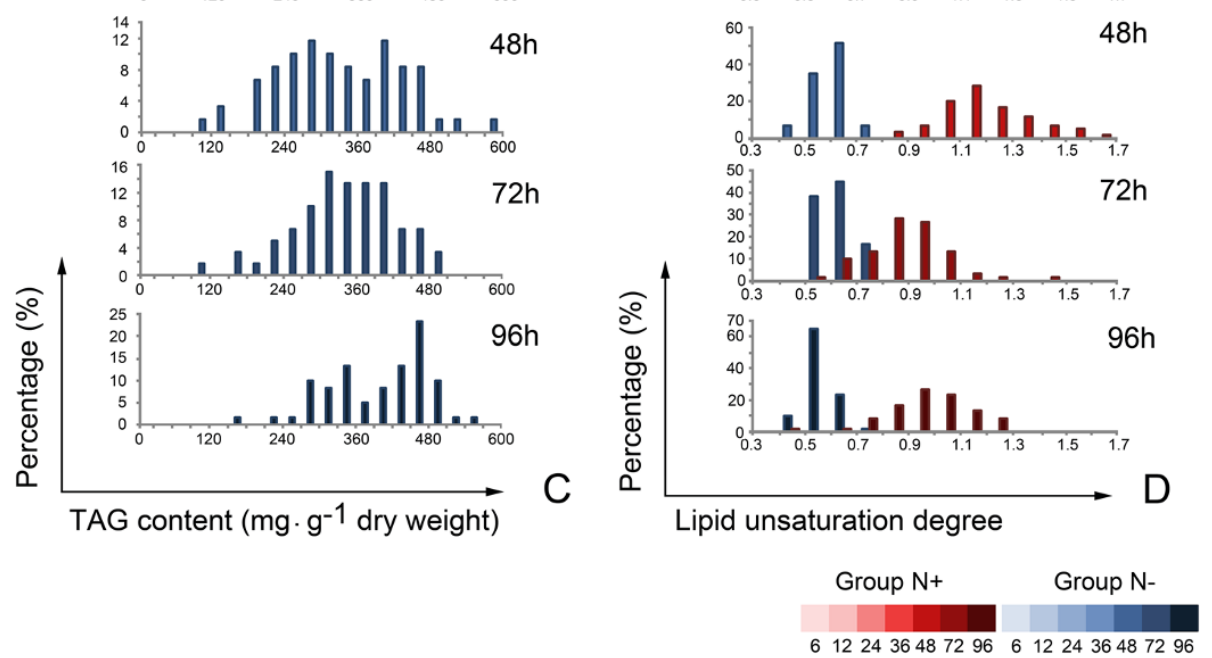

Figure 4 Quantitative analysis of TAG content and lipid unsaturation degree in single cells. (A) TAG content of individual cells as predicted by PLSR. Each square represents one Group N-cell. (B) Lipid unsaturation degree as determined by I $_{1656} / I_{1441}$. Each triangle represents one Group N + cell, and each square represents one Group N- cell. (C) Distribution of TAG content of Group N- cells at each time point. X axis is the predicted TAG content ( $\mathrm{mg} \mathrm{g}^{-1}$ dry weight), $Y$ axis is the percentage of cells. Since TAG content is increasing sharply, the range of $X$ axis is different between time points. (D) Distribution of lipid unsaturation degree of Group N- or Group N + cells at each time point. X axis is the lipid unsaturation degree, Y axis is the percentage of cells. h: hours; PLSR: partial least square regression; TAG: triacylglycerol.

Our findings further enabled modeling of the dynamics of population heterogeneity in terms of particular traits of interest. At each time point, both lipid unsaturation degree and TAG content of individual cells showed an approximate normal distribution, indicating the internal heterogeneity on the population level (Figure 4C and D). We have used the relative standard deviation (RSD) of measurements of multiple cells at the same time point to represent the population heterogeneity. During the continuous increase of TAG contents in Group N-cells over time, the heterogeneity of TAG content decreased accordingly. On the other hand, while the heterogeneity of lipid unsaturation in a population exhibited no monotonic changes in Group N + up to 96 hours, that of Group $\mathrm{N}$ - decreased continuously after 48 hours (Table 4). Both suggested that nitrogen-depletion stress might be a strategy for the homogenization of certain cell components in an algal population (Figure 5).

Recently, researchers have used Raman spectra to nonspecifically quantify the total cellular lipids in microalgae cell pastes (Chlorella sp.) using signal intensities of the range $2845-3107 \mathrm{~cm}^{-1}$ [21]. Here, we have for the first 
Table 4 Heterogeneity of TAG and lipid unsaturation degree as represented by RSD

\begin{tabular}{|c|c|c|c|c|c|c|c|}
\hline RSD value & $6 \mathrm{~h}$ & $12 \mathrm{~h}$ & $24 \mathrm{~h}$ & $36 \mathrm{~h}$ & $48 \mathrm{~h}$ & $72 \mathrm{~h}$ & $96 \mathrm{~h}$ \\
\hline Predicted TAG content (Group N-) & 0.602 & 0.748 & 0.643 & 0.485 & 0.305 & 0.249 & 0.211 \\
\hline Lipid unsaturation degree (Group N-) & 0.140 & 0.166 & 0.144 & 0.158 & 0.100 & 0.097 & 0.102 \\
\hline Lipid unsaturation degree (Group N+) & 0.168 & 0.150 & 0.122 & 0.104 & 0.141 & 0.182 & 0.162 \\
\hline
\end{tabular}

RSD: relative standard deviation; TAG: triacylglycerol; $h$ : hours.

time demonstrated the quantification of a particular lipid component of biotechnology interest in individual cells. In both industry and laboratorial cultures, synchronous growth is frequently desirable for optimum yield coefficients and yet can be difficult to sustain [8]. Moreover, the degree of metabolic and phenotypic heterogeneity can be different among cellular populations as it depends on species-specific genetic traits, and physiological features under particular microenvironment and culture conditions [35]. The ability of our method to track the degree of heterogeneity in the TAG level at single-cell resolution, when coupled with techniques such as phased cultures, tailor made biofilms and microfluidics devices [35,36], can be used to identify the most efficient oil producers, separate them from others and adapt them to favored conditions. It should therefore be of value to bioprocess optimization and control, as well as to the screening and engineering of oleaginous microalgae strains for enhanced oil productivity.

Moreover, recent studies have suggested that the cellular heterogeneity has profound biological implications [37]. Tracking of phenotypic traits and gene expression patterns at single-cell resolution can provide a deeper view of the population heterogeneity and help to understand the complicated behaviors of the populations and consortia [10]. Several studies have coupled gene expression and physiological parameters in individual cells. For example, analyses of volume, cell cycle and gene expression of individual yeast cells led to the identification of two mechanisms that regulate cell-to-cell variation in pathway capacity [38]. However, the connection between the stochastic gene expression and the physiological diversity within a population remains elusive [9]. Here, using the oleaginous microalga $N$. oceanica as a model, we have demonstrated rapid, label-free quantification of a particular lipid component of biotechnological interest in individual cells. For a given microalgae cell, the TAG concentration can then be coupled with gene expression analysis via Raman-activated cell sorting [29] and subsequent quantitative PCR or mRNA sequencing methods [39]. The phenotypes and genotypes at the level of single cells can thus be tested for correlations with each other and then compared to those at the population level [40], so as to elucidate the molecular mechanism underlying the phenotypic heterogeneity in an oleaginous cellular population.

Since SCRS offers real-time monitoring and bioprocess diagnosis capabilities without prior knowledge of any cellular component or metabolite as biomarker, and needs no labeling to the cell, its application may not be limited to the investigation of TAG accumulation, but also to bio-prospecting of novel phenotypes in yet-to-be-culture

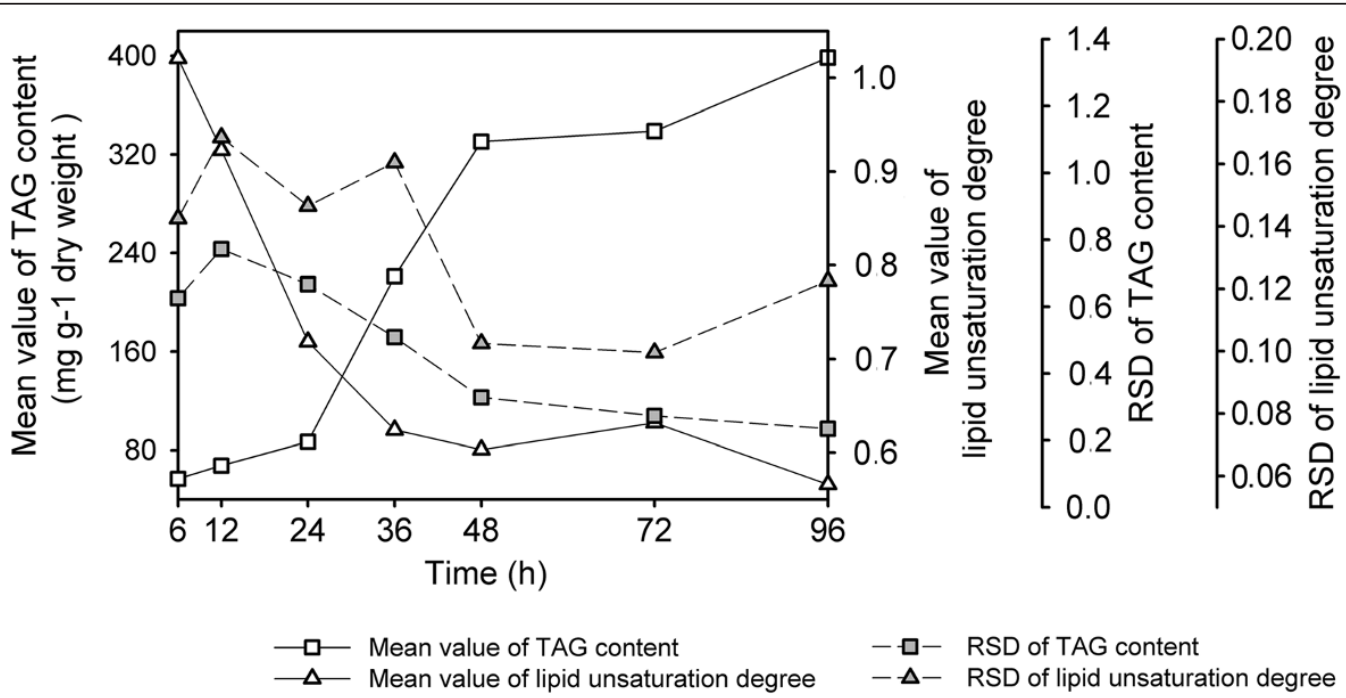

Figure 5 Comparison of TAG content and lipid unsaturation among Group N- cells. Mean value and RSD value of predicted TAG content and lipid unsaturation degree of Group N- cells at each time point were compared to show temporal patterns of population heterogeneity. h: hours; RSD: relative standard deviation; TAG: triacylglycerol. 
or mutant cells. Further development in hardware and software, such as microfluidics devices, and more statistical tools should allow for improvement of the specificity, sensitivity, spatial resolution and throughput of SCRS, and establish it as a general approach for characterization, screening, isolation and in-depth analysis of microbial cells or live-cell-mediated processes for broad applications $[11,41]$.

\section{Conclusions}

In this study, we demonstrated that SCRS for one individual microalgal cell acquired at sub-second level by $532 \mathrm{~nm}$ Raman spectroscopy are able to provide sufficient phenotypic information for the quantitative evaluation of its TAG content and the lipid unsaturation degree. In addition, comparison of SCRS among cells revealed the phenotypic heterogeneity of cells within an isogenic population. Therefore, SCRS is able to serve as a proxy for rapidly, quantitatively, and non-invasively tracking and screening the dynamics of cellular TAG contents in real-time, at single-cell level. It should also help with the investigation of the mechanisms behind functional heterogeneity within a cellular population.

\section{Methods}

\section{Microalgal growth}

$N$. oceanica IMET-1 cells were inoculated into a modified $\mathrm{f} / 2$ liquid medium with $4 \mathrm{mM} \mathrm{NO}_{3}{ }^{-}$under continuous light (approximately $50 \mu \mathrm{mol}$ photons $\mathrm{m}^{-2} \mathrm{~s}^{-1}$ ) at $25^{\circ} \mathrm{C}$ and aerated by bubbling with a mixture of $1.5 \% \mathrm{CO}_{2}$ in air. Composition of the medium was as below: $200 \mathrm{~g} / \mathrm{L}$ $\mathrm{KNO}_{3}, 25 \mathrm{~g} / \mathrm{L} \mathrm{NaH} \mathrm{PO}_{4} \cdot 2 \mathrm{H}_{2} \mathrm{O}, 5 \mathrm{~g} / \mathrm{L} \mathrm{FeCl}_{3} \cdot 6 \mathrm{H}_{2} \mathrm{O}, 4.5 \mathrm{~g} / \mathrm{L}$ EDTA and $1 \mathrm{~mL}$ of trace element solution $(\mathrm{pH}=$ 7.6). The trace element solution was comprised of $0.4 \mathrm{mg} / \mathrm{L} \mathrm{MnCl}_{2} \cdot 4 \mathrm{H}_{2} \mathrm{O}, 0.02 \mathrm{mg} / \mathrm{L} \mathrm{Na}_{2} \mathrm{MoO}_{4} \cdot 2 \mathrm{H}_{2} \mathrm{O}$, $0.02 \mathrm{mg} / \mathrm{L} \mathrm{CoCl}_{2} \cdot 6 \mathrm{H}_{2} \mathrm{O}, 0.02 \mathrm{mg} / \mathrm{L} \mathrm{CuSO}_{4} \cdot 5 \mathrm{H}_{2} \mathrm{O}$, $0.04 \mathrm{mg} / \mathrm{L} \mathrm{ZnSO}_{4} \cdot 7 \mathrm{H}_{2} \mathrm{O}, 1 \mu \mathrm{g} / \mathrm{L}$ vitamin $\mathrm{B}_{12}, 1 \mu \mathrm{g} / \mathrm{L}$ biotin and $200 \mu \mathrm{g} / \mathrm{L}$ thiamine $\cdot \mathrm{HCl}$. Cell density $\left(\mathrm{OD}_{750}\right)$ was determined in triplicate on a UV/Vis spectrophotometer (Beijing Purkinje General Instrument Co., Ltd., Beijing, China). Early-logarithmic phase algal cells were collected, washed three times with axenic seawater and re-inoculated with equal concentration in annular glass columns, either under the same condition as above (nitrogen-replete, or Group $\mathrm{N}+$ ) or with no $\mathrm{NO}_{3}{ }^{-}$supplemented (nitrogendepleted, or Group N-). Re-inoculation was performed in triplicate.

\section{Single-cell Raman microspectroscopy}

Cell aliquots were collected right before re-inoculation (at 0 hours), and from each triplicate of Group $\mathrm{N}+$ and Group N- at seven time points afterward: 6, 12, 24, 36, 48, 72 and 96 hours. Each cell sample was washed and re-suspended with $\mathrm{ddH}_{2} \mathrm{O}$ to avoid the high noise introduced by the culture media, and was immediately loaded into a capillary tube $(50 \mathrm{~mm}$ length $\times 1 \mathrm{~mm}$ width $\times 0.1 \mathrm{~mm}$ height, Camlab, Cambridge, UK) for measurement [42]. The Raman spectra of individual cells were acquired using a Raman Activated Cell Sorting system (RACS, Wellsens Inc, Beijing, China), which was equipped with a confocal microscope with a $50 \times$ PL magnifying dry objective (NA $=0.55$, BX41, Olympus UK Ltd., Southall, UK) and a $532 \mathrm{~nm} \mathrm{Nd:YAG} \mathrm{laser} \mathrm{(Ventus,} \mathrm{Laser}$ Quantum Ltd, Stockport, UK). The laser power out of the objective was $50 \mathrm{~mW}$. Individual microalgae in the capillary tube was captured and measured by the same 532-nm laser. The whole process, including a single-cell capture and Raman measurement, was performed within one second. The scattered photons were collected by a Newton EMCCD (Andor, Belfast, UK) utilizing a $1600 \times 200$ array of $16 \mu \mathrm{m}$ pixels with thermoelectric cooling down to $-70^{\circ} \mathrm{C}$ for negligible dark current. Each Raman spectrum was acquired between the range $3256 \mathrm{~cm}^{-1}$ and $273 \mathrm{~cm}^{-1}$, with a spectral resolution of $2 \mathrm{~cm}^{-1}$ achieved by a 300 groove $\mathrm{mm}^{-1}$ grating in the spectrograph. Sixty individual cells were measured for the sample at 0 hours, and twenty were measured in each of all other samples. For each sample, a background spectrum was generated as the average of five spectra acquired from the liquid around the cell.

Pre-processing of raw spectra was performed with LabSpec 5 (HORIBA Scientific, Orsay, France), including background subtraction and the baseline correction by a polynomial algorithm with a degree of seven. Two regions of the spectra: the biochemical fingerprint region $\left(800 \mathrm{~cm}^{-1}\right.$ to $\left.1800 \mathrm{~cm}^{-1}\right)$ and the hydrocarbon region $\left(2600 \mathrm{~cm}^{-1}\right.$ to $\left.3100 \mathrm{~cm}^{-1}\right)$, were extracted for further analyses in order to extract useful information contained in Raman bands from the useless noise [28,43]. For both regions a spectrum was normalized via division by its area. The lipid unsaturation degree in each cell was calculated as the ratio of Raman intensity of the $\mathrm{C}=\mathrm{C}$ stretch and the intensity of $\mathrm{CH}_{2}$ bend, namely $\mathrm{I}_{1656} / \mathrm{I}_{1441}$, as described previously [20].

\section{Determination of cellular lipid content by LC-MS}

LC-MS was performed on the same cell aliquots which were sampled for SCRS, at 0 hours and each triplicate of the six time points: $6,12,24,48,72$ and 96 hours. A quantitative LC-MS method was used to determine the cellular content of molecular lipid species belonging to nine major glycerolipid classes including TAG, monogalactosyldiacylglycerol (MGDG), digalactosyldiacylglycerol (DGDG), sulfoquinovosyldiacylglycerol (SQDG), diacylglycerol-O-(N, $\mathrm{N}, \mathrm{N}$-trimethyl)-homoserine (DGTS), phosphatidylcholine (PtdCho), phosphatidylethanolamine (PE), phosphatidylglycerol (PG) and phosphatidylinositol (PI). These nine main lipid classes, including 74 lipid species, constitute 
the majority of total lipids in Nannochloropsis cells [44,45]. Total lipids were extracted with chloroform:methanol (2:1, $\mathrm{w} / \mathrm{w})$ and recovered in chloroform: methanol (1:1) before being loaded for quantification. An Agilent 6460 triple quadruple electrospray ionization mass spectrometer equipped with a 1260 high performance liquid chromatography (Agilent Technologies, Santa Clara, CA, United States) was used for LC-MS analysis. PtdCho, PE, DGTS, TAG, MGDG and DGDG were detected at the positive mode, with the mobile phases of methanol : acetonitrile: $\mathrm{H}_{2} \mathrm{O}(19: 19: 2 ; A)$ and isopropanol (B) containing 0.1\% formic acid and $10 \mathrm{mM}$ ammonium acetate. PI, PG and SQDG were detected at the negative mode with the mobile phases of $85 \%$ methanol (A) and isopropanol containing $0.025 \% \mathrm{NH}_{4} \mathrm{OH}$. The LC gradients for positive mode were as follows: 0 minutes, $90 \% \mathrm{~A}$ and $10 \% \mathrm{~B} ; 5$ minutes $90 \% \mathrm{~A}$ and $10 \% \mathrm{~B}$; 25 minutes, $60 \% \mathrm{~A}$ and $40 \% \mathrm{~B}$; $60 \mathrm{mi}-$ nutes $45 \% \mathrm{~A}$ and $55 \% \mathrm{~B}$; 66 minutes, 45\% A and 55\% B; 68 minutes $90 \%$ A and $10 \%$ B. For negative mode, the LC gradients were as follows: 0 minutes, $95 \% \mathrm{~A}$ and $5 \% \mathrm{~B}$; 15 minutes, $85 \% \mathrm{~A}$ and $15 \% \mathrm{~B}, 22$ minutes $45 \% \mathrm{~A}$ and $55 \% \mathrm{~B} ; 42$ minutes, $45 \% \mathrm{~A}$ and $55 \% \mathrm{~B}$; 44 minutes $95 \% \mathrm{~A}$ and $5 \% \mathrm{~B}$. The flow rate was $0.2 \mathrm{~mL} \mathrm{~min}^{-1}$. Nitrogen was used as nebulizing gas (at $0.3 \mathrm{Bar}$ ) and a dry gas $\left(4 \mathrm{~L} \mathrm{~min}^{-1}\right.$ at $200^{\circ} \mathrm{C}$ ). The spray capillary voltage was $3700 \mathrm{~V}$ for the negative ion mode and $4200 \mathrm{~V}$ for the positive ion mode. For quantification of lipid content, TAG 51:0 (17:0/17:0/ 17:0), MGDG 36:0 (18:0/18:0), DGDG 36:0 (18:0/18:0), PE 31:1 (14:1/17:0) and PG 37:4 (17:0/20:4) were used as the internal standard (ITSD) for TAG, MGDG, DGDG, PE and PG respectively. PtdCho 37:4 (17:0/20:4) was used as ITSD for both PtdCho and DGTS, and PI 37:4 (17:0/20:4) for both PI and SQDG. TAG 48:3 (16:1/16:1/16:1), TAG 50:1 (16:0/18:1/16:0), TAG 52:2 (18:1/16:0/18:1) and TAG $54: 3(18: 1 / 18: 1 / 18: 1)$ were used as calibration standards for 48 carbon, 50 carbon, 52 carbon and 54 carbon TAG quantifications, respectively. MGDG 34:6 (16:3/ 18:3), DGDG 36:3 (18:3/18:3), PE 36:1 (18:0/18:1), PG 36:1 (18:0/18:1), PtdCho 36:2 (18:1/18:1) and DGTS 32:0 (16:0/ $16: 0)$ were used as calibration standards for their corresponding lipid class.

The ratio of the number of $\mathrm{C}=\mathrm{C}$ bonds and the number of $\mathrm{CH}_{2}$ bonds of each lipid species was calculated to represent the unsaturation degree of this lipid species as previously described [20]. The unsaturation degree of the total cellular lipid of each culture was then calculated by multiplying the unsaturation degree of each lipid species by its relative abundance in the cellular extract $(\mu \mathrm{mol} / \mathrm{g}$ dry weight).

\section{Chemometrics analyses}

The normalized fingerprint and hydrocarbon regions of spectra from each cell were used separately for PCA based on Euclidean distances [46], followed by LDA based on the principal components extracted by PCA. Both PCA and LDA use linear combinations of the original variables (wavenumbers of the spectra) as PCs to characterize the ordination of samples or to discriminate two or more classes of samples. The first few PCs were used for LDA instead of the original variables in order to reduce the dimensionality of the variation. For the LDA-discriminating cells between $\mathrm{N}+$ and $\mathrm{N}$ - conditions at separate time points, 15 out of 20 cells from each triplicate of the two conditions were randomly selected and combined for the construction of a training dataset $(n=90)$, and the rest of the cells were used to form a test dataset $(n=30)$. For the LDA-discriminating cells at 0 hours and Group N-cells at different time points, 45 out of 60 cells at 0 hours and 15 out of 20 cells from each triplicate at the seven time points afterwards, were randomly selected and combined for the construction of a training dataset $(n=360)$, and the rest of the cells were used to form a test dataset $(n=120)$. Leaveone-out cross validation (LOOCV) was used to evaluate the reliability of the LDA model based on the training dataset, followed by challenging the model with the test dataset. The misclassification rates of both the training and test dataset were calculated to determine an optimal number of PCs [47]. The test dataset was rotated into a new dataset of PCs by the loadings of the PCA of the training dataset as described previously, so as to convert two datasets in the same spectral space [28].

SCRS data is used to construct a PLSR model together with the TAG content of corresponding samples determined by LC-MS. By relating two datasets X (SCRS in our study) and y (TAG content by LC-MS in our study) by means of regression, PLSR performs a multivariate calibration in order to establish a linear model which enables the prediction of $\mathrm{y}$ from measured dataset $\mathrm{X}$. In the regression process, decomposition of $\mathrm{X}$ is performed under the consideration of $y$ in a simultaneous analysis of the two datasets [48]. Specifically, the SCRS of all 60 cells at 0 hours, and that of each of the 20 cells from triplicates at 6, 12, 24, 48, 72, and 96 hours were averaged separately, generating data of 19 combined Raman spectra as a matrix (designated as X). Among them, two of the triplicates at $6,12,24,48,72$ and 96 hours were randomly selected and combined with the 0 hour data to form a training dataset for the calibration of the model (Xc, $n=13)$, and the rest were used as a test dataset for validation $(X v, n=6)$. Correspondingly, TAG content of 0 hours culture and each triplicate culture at $6,12,24,48,72$, and 96 hours were measured by LC-MS, generating data of another 19 values as a vector (designated as $\mathrm{y}$ ), also including the training dataset $(y c, n=13)$ and the test dataset $(y v, n=6)$. Firstly, the PLSR model was established using Xc and yc data. Secondly, Xv data and the function of the established model were used to predict the $\mathrm{yv}$ value. The predicted yv 
value was compared with the measured yv value. Reliability of the model was assessed by the MSEC of the training set by LOOCV, as well as the squared correlation coefficient $\left(R^{2}\right)$ between predicted and measured y values in both the training set and the test set. Finally, the function was utilized for the prediction of TAG content in single Group N- cells (as y value) at each time point between 6 and 96 hours using individual SCRS (as X data). PCA, LDA and PLSR were performed with Matlab R2010a (Mathworks, Natick, Massachusetts, United States). Other statistical analyses were performed with SPSS Statistics 17.0 (SPSS Inc, Chicago, Illinois, United States).

\section{Additional files}

\section{Additional file 1: Impact of the laser power on microalgal cell. A}

single N. oceanica IMET1 cell was optically trapped by a $532 \mathrm{~nm}$ laser and its Raman spectrum was recorded in one second by the same laser. No loss of cell activity was observed, our measurement thus does not seem to have a significant negative impact on the health state of the cell.

Additional file 2: Cellular content of the $\mathbf{7 4}$ lipid species in cultures under nitrogen depletion conditions. The cellular contents of each species of the nine lipid classes (TAG, DGDG, MGDG, DGTS, SQDG, PI, PG, $P($ and $\mathrm{PE}$ ) along the time course were listed.

Additional file 3: Correlation between the TAG content and lipid unsaturation degree at single-cell level and population level. (A) Correlation between TAG content and lipid unsaturation degree at the single-cell level as measured by SCRS. Each dot represents one cell in the $\mathrm{N}$ - cultures. (B) Correlation between TAG content and lipid unsaturation degree at the population level as measured by LC-MS. Each dot represents one culture under the $\mathrm{N}$ - conditions (each triplicate at 6, 12, 24, 48, 72 and 96 hours).

\section{Abbreviations \\ DGDG: digalactosyldiacylglycerol; DGTS: diacylglycerol-O-(N,N,N-trimethyl)- homoserine; EMCCD: electron multiplying charge coupled device; ITSD: internal standard; LC-MS: liquid chromatography/mass spectrometry; LDA: linear discriminant analysis; LOOCV: leave-one-out cross validation; MCR: misclassification rate; MGDG: monogalactosyldiacylglycerol; MSEC: mean squared error of calibration; NMR: nuclear magnetic resonance; OD: optical density; PC: principal component; PCA: principal component analysis; PE: phosphatidylethanolamine; PG: phosphatidylglycerol; PI: phosphatidylinositol; PLSR: partial least square regression; PtdCho: phosphatidylcholine; RSD: relative standard deviation; SCRS: single-cell Raman spectra; SD: standard deviation; SDM: standard deviation of the mean; SQDG: sulfoquinovosyldiacylglycerol; TAG: triacylglycerol.}

\section{Competing interests}

The authors declare that they have no competing interests.

\section{Authors' contributions}

TW, YJ, WH and JX designed the research. TW and SH analyzed data. YJ and YW performed Raman spectrometry experiments. JJ, JL, DH and QH performed algal cultivation and LC-MS experiments. TW, WH and JX wrote the manuscript. YJ, YW, JJ, JL, SH, DH and QH revised the manuscript and provided critical suggestions. All authors read and approved the final version of the manuscript.

\section{Acknowledgements}

This work was supported by the National Basic Research Program (2012CB721101), the High-Tech Development Program (2012AA02A707), and the Methodology Innovation Program (2011IM030100) from the Ministry of Science and Technology of China, and the Microevolution Program (91231205) from the National Natural Science Foundation of China. We are also grateful for the support of the International Innovation Partnership Program from the Chinese Academy of Sciences.

\section{Author details}

${ }^{1}$ Single-Cell Center, CAS Key Laboratory of Biofuels and Shandong Key Laboratory of Energy Genetics, Qingdao Institute of BioEnergy and Bioprocess Technology, Chinese Academy of Sciences, 189 Songling Road, Qingdao, Shandong 266101, China. ${ }^{2}$ Kroto Research Institute, University of Sheffield, Broad Lane, Sheffield, South Yorkshire S3 7HQ, United Kingdom. ${ }^{3}$ Laboratory for Algae Research and Biotechnology, College of Technology and Innovation, Arizona State University, 7417 E. Unity Avenue, Mesa, Arizona 85212, USA

Received: 10 October 2013 Accepted: 27 March 2014

Published: 9 April 2014

\section{References}

1. Wijfels RH, Barbosa MJ: An outlook on microalgal biofuels. Science 2010, 329:796-799.

2. Georgianna DR, Mayfield SP: Exploiting diversity and synthetic biology for the production of algal biofuels. Nature 2012, 488:329-335.

3. Guschina IA, Harwood JL: Lipids and lipid metabolism in eukaryotic algae. Prog Lipid Res 2006, 45:160-186.

4. Hu Q, Sommerfeld M, Jarvis E, Ghirardi M, Posewitz M, Seibert M, Darzins A: Microalgal triacylglycerols as feedstocks for biofuel production: perspectives and advances. Plant J 2008, 54:621-639.

5. Pruvost J, Van Vooren G, Cogne G, Legrand J: Investigation of biomass and lipids production with Neochloris oleoabundans in photobioreactor. Bioresource Technol 2009, 100:5988-5995.

6. Yu ET, Zendejas FJ, Lane PD, Gaucher S, Simmons BA, Lane TW: Triacylglycerol accumulation and profiling in the model diatoms Thalassiosira pseudonana and Phaeodactylum tricornutum (Baccilariophyceae) during starvation. J Appl Phycol 2009, 21:669-681.

7. Craigie JS, MacKinnon SL, Walter JA: Liquid seaweed extracts identified using H-1 NMR profiles. J Appl Phycol 2008, 20:665-671.

8. Muller $\mathrm{S}$, Harms H, Bley T: Origin and analysis of microbial population heterogeneity in bioprocesses. Curr Opin Biotech 2010, 21:100-113.

9. Lidstrom ME, Konopka MC: The role of physiological heterogeneity in microbial population behavior. Nat Chem Biol 2010, 6:705-712.

10. Eldar A, Elowitz MB: Functional roles for noise in genetic circuits. Nature 2010, 467:167-173

11. Wang DJ, Bodovitz S: Single cell analysis: the new frontier in 'omics'. Trends Biotechnol 2010, 28:281-290.

12. Huang WE, Li M, Jarvis RM, Goodacre R, Banwart SA: Shining light on the microbial world the application of Raman microspectroscopy. Adv Appl Microbiol 2010, 70:153-186.

13. Pelletier MJ: Quantitative analysis using Raman spectrometry. Appl Spectrosc 2003, 57:20a-42a.

14. Huang WE, Griffiths RI, Thompson IP, Bailey MJ, Whiteley AS: Raman microscopic analysis of single microbial cells. Anal Chem 2004, 76:4452-4458.

15. Li M, Xu J, Romero-Gonzalez M, Banwart SA, Huang WE: Single cell Raman spectroscopy for cell sorting and imaging. Curr Opin Biotechnol 2012 23:56-63.

16. Wang $Y$, Song $Y Z$, Zhu $D$, Ji $Y T$, Wang TT, Mcllvenna $D$, Yin $H B$, Xu J, WE H: Probing and sorting single cells - the application of a Raman-activated cell sorter. Spectrosc Eur 2013, 25:16-20.

17. Chen W, Zhang CW, Song LR, Sommerfeld M, Hu Q: A high throughput Nile red method for quantitative measurement of neutral lipids in microalgae. J Microbiol Meth 2009, 77:41-47.

18. Huang YY, Beal CM, Cai WW, Ruoff RS, Terentjev EM: Micro-Raman spectroscopy of algae: composition analysis and fluorescence background behavior. Biotechnol Bioeng 2010, 105:889-898.

19. Weiss TL, Chun HJ, Okada S, Vitha S, Holzenburg A, Laane J, Devarenne TP: Raman spectroscopy analysis of botryococcene hydrocarbons from the green microalga Botryococcus braunii. J Biol Chem 2010, 285:32458-32466.

20. Wu HW, Volponi JV, Oliver AE, Parikh AN, Simmons BA, Singh S: In vivo lipidomics using single-cell Raman spectroscopy. Proc Natl Acad Sci U S A 2011, 108:3809-3814. 
21. Lee TH, Chang JS, Wang HY: Rapid and in Vivo quantification of cellular lipids in Chlorella vulgaris using near-infrared Raman spectrometry. Anal Chem 2013, 85:2155-2160.

22. Wang D, Lu Y, Huang $H, X u$ J: Establishing oleaginous microalgae research models for consolidated bioprocessing of solar energy. Adv Biochem Eng Biotechnol 2012, 128:69-84.

23. Huang WE, Ward AD, Whiteley AS: Raman tweezers sorting of single microbial cells. Environ Microbiol Rep 2009, 1:44-49.

24. Ghesti GF, De Macedo JL, Resck IS, Dias JA, Dias SCL: FT-Raman Spectroscopy quantification of biodiesel in a progressive soybean oil transesterification reaction and its correlation with $\mathrm{H}-1$ NMR Spectroscopy methods. Energy Fuel 2007, 21:2475-2480.

25. Chan JW, Taylor DS, Lane SM, Zwerdling T, Tuscano J, Huser T: Nondestructive identification of individual leukemia cells by laser trapping Raman spectroscopy. Anal Chem 2008, 80:2180-2187.

26. Vega JMP, Roa MAC, Saavedra MPS, Ramírez DT, Dávalos CR: Effect of culture medium and nutrient concentration on fatty acid content of Chaetoceros muelleri. Rev Latinoam Biotecnol Amb Algal 2010, 1:6-15.

27. Li YQ, Horsman M, Wang B, Wu N, Lan CQ: Effects of nitrogen sources on cell growth and lipid accumulation of green alga Neochloris oleoabundans. Appl Microbiol Biot 2008, 81:629-636.

28. Stockel S, Meisel S, Elschner M, Rosch P, Popp J: Identification of Bacillus anthracis via Raman spectroscopy and chemometric approaches. Anal Chem 2012, 84:9873-9880.

29. Wang $Y$, Ji YT, Wharfe ES, Meadows $R$, March $P$, Goodacre $R$, XU J, WE H: Rapid Raman activated cell ejection for isolation of single cells. Anal Chem 2013, 85:10697-10701.

30. Liang Y, Beardall J, Heraud P: Effects of nitrogen source and UV radiation on the growth, chlorophyll fluorescence and fatty acid composition of Phaeodactylum tricornutum and Chaetoceros muelleri (Bacillarlophyceae). J Photoch Photobio B 2006, 82:161-172.

31. Heraud P, Beardall J, McNaughton D, Wood BR: In vivo prediction of the nutrient status of individual microalgal cells using Raman microspectroscopy. Fems Microbiol Lett 2007, 275:24-30.

32. Wold S, Sjostrom M, Eriksson L: PLS-regression: a basic tool of chemometrics. Chemometr Intell Lab 2001, 58:109-130.

33. Almeida MR, Alves RS, Nascimbem LBLR, Stephani R, Poppi RJ, De Oliveira LFC: Determination of amylose content in starch using Raman spectroscopy and multivariate calibration analysis. Anal Bioanal Chem 2010, 397:2693-2701.

34. Ewanick SM, Thompson WJ, Marquardt BJ, Bura R: Real-time understanding of lignocellulosic bioethanol fermentation by Raman spectroscopy. Biotechnol Biofuels 2013, 6:28

35. Schweder T, Krüger E, Xu B, Jürgen B, Blomsten G, Enfors S-O, Hecker M: Monitoring of genes that respond to process related stress in large scale bioprocesses. Biotechnol Bioeng 1999, 65:151-159.

36. Fritzsch FSO, Dusny C, Frick O, Schmid A: Single-cell analysis in biotechnology, systems biology, and biocatalysis. Annu Rev Chem Biomol 2012, 3:129-155.

37. Avery SV: Microbial cell individuality and the underlying sources of heterogeneity. Nat Rev Microbiol 2006, 4:577-587.

38. Colman-Lerner A, Gordon A, Serra E, Chin T, Resnekov O, Endy D, Pesce CG, Brent R: Regulated cell-to-cell variation in a cell-fate decision system. Nature 2005, 437:699-706.

39. Tang F, Barbacioru C, Nordman E, Li B, Xu N, Bashkirov VI, Lao K, Surani MA: RNA-Seq analysis to capture the transcriptome landscape of a single cell. Nat Protoc 2010, 5:516-535.

40. Wang D, Ning K, Li J, Hu J, Han D, Wang H, Zeng X, Jing X, Zhou Q, Su X, Chang X, Wang A, Wang W, Jia J, Wei L, Xin Y, Qiao Y, Huang R, Chen J, Han B, Yoon K, Hill RT, Zohar Y, Chen F, Hu Q, Xu J: Nannochloropsis genomes reveal evolution of microalgal oleaginous traits. PLOS Genet 2014, 10:e1004094.

41. Dewan A, Kim J, McLean RH, Vanapalli SA, Karim MN: Growth kinetics of microalgae in microfluidic static droplet arrays. Biotechnol Bioeng 2012, 109:2987-2996.

42. Li MQ, Canniffe DP, Jackson PJ, Davison PA, FitzGerald S, Dickman MJ, Burgess JG, Hunter CN, Huang WE: Rapid resonance Raman microspectroscopy to probe carbon dioxide fixation by single cells in microbial communities. Isme J 2012, 6:875-885.

43. Hu P, Borglin S, Kamennaya NA, Chen L, Park H, Mahoney L, Kijac A, Shan G, Chavarria KL, Zhang CM, Quinn NWT, Wemmer D, Holman H-Y, Jansson C: Metabolic phenotyping of the cyanobacterium Synechocystis 6803 engineered for production of alkanes and free fatty acids. Appl Energy 2013, 102:850-859.

44. Sukenik A, Yamaguchi Y, Livne A: Alterations in lipid molecular-species of the marine eustigmatophyte Nannochloropsis sp. J Phycol 1993, 29:620-626.

45. Simionato D, Block MA, La Rocca N, Jouhet J, Marechal E, Finazzi G, Morosinotto T: The response of Nannochloropsis gaditana to nitrogen starvation includes de novo biosynthesis of triacylglycerols, a decrease of chloroplast galactolipids, and reorganization of the photosynthetic apparatus. Eukaryot Cell 2013, 12:665-676.

46. Endres DM, Schindelin JE: A new metric for probability distributions. IEEE Trans Inf Theory 2003, 49:1858-1860.

47. Mazurek S, Szostak R: Quantitative determination of prednisone in tablets by infrared attenuated total reflection and Raman spectroscopy. J AOAC Int 2012, 95:744-750.

48. Wold S, Martens $H$, Wold H: The multivariate calibration-problem in chemistry solved by the PLS method. Lect Notes Math 1983, 973:286-293.

doi:10.1186/1754-6834-7-58

Cite this article as: Wang et al:: Quantitative dynamics of triacylglycerol accumulation in microalgae populations at single-cell resolution revealed by Raman microspectroscopy. Biotechnology for Biofuels 2014 7:58

\section{Submit your next manuscript to BioMed Central and take full advantage of:}

- Convenient online submission

- Thorough peer review

- No space constraints or color figure charges

- Immediate publication on acceptance

- Inclusion in PubMed, CAS, Scopus and Google Scholar

- Research which is freely available for redistribution 